\title{
Intergenerational Persistence in Income and Social Class: The Impact of Within-Group Inequality
}

\author{
Jo Blanden*, Paul Gregg** and Lindsey Macmillan**
}

March 2012

* Department of Economics, University of Surrey and Centre for Economic Performance, London School of Economics

** Department of Economics, University of Bristol and Centre for Market and Public Organisation, University of Bristol

\begin{abstract}
$\underline{\text { Abstract }}$
Family income is found to be more closely related to sons' earnings for a cohort born in 1970 compared to one born in 1958. This result is in stark contrast to the finding on the basis of social class; intergenerational mobility for this outcome is found to be unchanged. Our aim here is to explore the reason for this divergence. We derive a formal framework which relates mobility as measured by family income/earnings to mobility as measured by social class. Building on this framework we then test a number of alternative hypotheses to explain the difference between the trends. We find evidence of an increase in the intergenerational persistence of the permanent component of income that is unrelated to social class. We reject the hypothesis that the observed decline in income mobility is a consequence of the poor measurement of permanent family income in the 1958 cohort.
\end{abstract}

JEL codes: J13, J31, Z13

Keywords: Intergenerational income mobility, social class fluidity, income inequality.

\section{Acknowledgements:}

We would like to thank Anders Björklund, Stephen Machin, Sandra McNally, Elizabeth Washbrook, Christian Dustmann, Patrick Sturgis, Robert Erikson and John Goldthorpe for their helpful comments. We also appreciate the comments of the editors and referees who have helped to substantially improve the paper. 


\section{Introduction}

Both economists and sociologists measure the intergenerational persistence of socioeconomic status, with economists tending to use income or earnings as the measure of status (for surveys see Solon, 1999, Black and Devereux, 2010) while sociologists use fathers' social class (Erikson and Goldthorpe, 1992) or an index of occupational status (Blau and Duncan, 1967). To ascertain whether the measured extent of mobility is high or low, both literatures have asked: i) how does mobility compare across nations? ii) has mobility increased or decreased across time? For both of these comparisons the findings of economists and sociologists contrast sharply for the UK.

International comparisons of income mobility place the UK as a country with low mobility (Corak, 2006) whereas those using the measure of social class/occupational status tend to rank it closer to the middle (Erikson and Goldthorpe 1992, Breen, 2004). Crosscountry rankings across the two approaches are very weakly correlated with each other (Blanden, 2011). Similar ambiguity exists when comparing trends in intergenerational mobility across time. Blanden, Goodman, Gregg and Machin (2004) find that intergenerational income mobility decreases for a cohort born in 1970 (British Cohort Study) compared to a cohort born in 1958 (National Child Development Study) while Goldthorpe and Jackson (2007) find no change in social class mobility for the same datasets. Our aim in this research is to analyse the factors responsible for the difference in the measured trends in mobility. Our interest in trends is driven, in part, by wide acceptance of the finding of falling mobility among politicians and commentators and its contribution to the sense that Britain has a 'mobility problem' (Goldthorpe and Jackson, 2007, Blanden, 2010 and Saunders, 2010). It is therefore crucial to examine the robustness of this result given the contrary results emanating from the literature that uses social class as the relevant measure.

In addition, we aim to draw out the conceptual links between mobility as measured by economists and sociologists and therefore offer a fresh perspective on both literatures. The divergent results may simply reflect underlying conceptual differences. Economists are aiming to measure economic resources whereas class reflects workplace autonomy and broader social capital (Goldthorpe, 2000). However, the view we adopt here is that both approaches are trying to assess long-term or permanent socio-economic status but measure it in different ways. In principle there are advantages and disadvantages to both measurement approaches. Erikson and Goldthorpe use a seven-category class schema, and might therefore only capture a limited amount of the potential variation in permanent economic status between families (see critiques by Grusky and Weeden 2001 and McIntosh and Munk 2009). 
In addition, mobility measures based on fathers' social class or fathers' earnings will ignore the contribution of mothers. Recently economists have moved to using measures of parental income in the first generation to account for this increasingly important contribution (Lee and Solon, 2009, Aaronson and Mazumder, 2008). However, social class measures are sometimes argued to be better at measuring the most important aspects of the permanent status of the family (see Goldthorpe and McKnight, 2006). A particular difficulty with the income data that we use from the cohort studies is that it is measured based on a single interview where families are asked about their current income. Erikson and Goldthorpe (2010) and Saunders (2010) suggest that social class is a more reliable measure than current income and that the differing results between the two approaches are explicable by the poor measurement of family income in the 1958 cohort.

We begin our analysis by formulating a framework to examine the relationship between permanent income, social class and current income. This framework is then explored empirically using the British Household Panel Survey (BHPS). We find that there is a substantial portion of permanent income which is unrelated to social class. Conceptually, this component can account for the divergent results. Section 3 of the paper outlines the main results concerning the trend in mobility over the British cohorts using both economic and sociological methodologies and addresses the main issues concerning data and measurement. We focus on a number of specific measurement issues in the National Child Development Study (NCDS) which might explain our result that income mobility is greater in the earlier cohort compared with the later British Cohort Study (BCS). We find no evidence to support the hypothesis that data quality or differential measurement is generating the observed decline in mobility.

In Section 4 we detail other potential mechanisms that could generate different trends in measured income and social class mobility. To do this we show that current income can be decomposed into a number of different components. As mentioned above, the permanent component can be split into the part associated with social class, and the residual part, which we refer to as within-class permanent income. In addition current measured income will include transitory error (the difference between current and permanent income) and finally any mismeasurement. We then establish four alternative testable hypotheses that could account for the diverging trends in mobility. In brief they are as follows: (1) the link between fathers' social class and family income within generations has changed, perhaps due to the increasing role of women in accounting for family socio-economic position; (2) the 
divergence is due to differential measurement error across the cohorts; (3) within-class permanent income has become more important in determining children's outcomes; and (4) differences can be explained by a decline in the transitory component of parental income.

We find no evidence that a change in the mapping from father's social class to income affects our results; instead we find that a substantial part of the increased persistence across generations can be predicted by observable short and long-run income proxies. Indeed, it is possible to plausibly account for the full rise in income persistence through the increased persistence of within-class permanent income. This is fully consistent with the data examination which finds no evidence that the differential results could be explained by measurement problems. In summary, it appears that explanation (3) above, is the most likely.

\section{Measuring permanent income}

\subsection{The components of income}

Here we set out a framework which demonstrates the relationships between permanent family income, income at a point in time and fathers' social class. This provides clear foundations for our examination of the reasons behind the divergent results regarding intergenerational mobility as measured by income or social class.

For economists, the intergenerational relationship of interest is the relationship between parents' permanent income and the child's permanent income. $\mathrm{y}^{*}$ represents the log of permanent income with subscripts $\mathrm{p}$ and $\mathrm{s}$ referring to the parents and child (son).Intergenerational mobility can be summarised by $\hat{\beta}$, the estimate of the coefficient $\beta$ from the following equation:

$$
y_{s i}^{*}=\alpha+\beta y_{p i}^{*}+u_{i}
$$

The focus on sons here simplifies the analysis so that we are focusing on male social class in both generations and to reduce the issues resulting from endogenous labour market participation (a lot more important for women). Note that we are considering an asymmetric relationship, relating combined parental income to the sons' own earnings. We take care to reflect this asymmetry in the rest of the paper and we explicitly consider the role of mothers' earnings as part of our first hypothesis in Section 4 below.

The intergenerational correlation, $r$, is also of interest in cross-cohort studies as this adjusts $\beta$ for any changes in variance that occur across cohorts. $\hat{r}$ is calculated by adjusting $\hat{\beta}$ by the sample standard deviations of parental income and child's income. Björklund and 
Jäntti (2009) urge the more widespread use of this statistic when making international comparisons of mobility and the same arguments apply when considering trends over time.

$$
\hat{r}=\hat{\beta} \frac{\left(\hat{\sigma}^{y_{p}^{*}}\right)}{\left(\hat{\sigma}^{y_{s}^{*}}\right)}
$$

Following Björklund and Jäntti (2000), permanent parental income can be decomposed into the part that is associated with fathers' social class (in our exposition social class is denoted by a continuous variable $S C_{f i}$, but categorical variables are used in our analysis; the subscript $\mathrm{f}$ represents father) and $v_{p} \cdot v_{p}$ is the parents' permanent income that is uncorrelated with fathers' social class.

$y_{p i}^{*}=\delta_{p} S C_{f i}+v_{p i}$

$\delta_{p}$ will reflect the relationships with fathers' social class and of all the different components which make up total income: fathers' and mothers' earnings and unearned income. This is a point we shall return to later. The child's permanent income can also be split into similar components: the part that is related to the child's own class and the part that is independent of this.

$$
y_{s i}^{*}=\delta_{s} S C_{s i}+v_{s i}
$$

Unfortunately, permanent income is generally not available for intergenerational research (see Solon, 1992 for the first discussion of resulting biases) and the British cohort studies suffer from this limitation. Measured current parental income is permanent income plus the deviation between current measured income and permanent income $\left(e_{p i}\right)$. Later in the analysis we will explore the components that make up this term, but for now we consider it to be anything which leads to a difference between measured and permanent income. Measures of current income are related to these components as follows:

$$
\begin{gathered}
y_{p i}=\delta_{p} S C_{f i}+v_{p i}+e_{p i} \\
y_{s i}=\delta_{s} S C_{s i}+v_{s i}+e_{s i}
\end{gathered}
$$

Under classical measurement error assumptions that the level of measured $y_{i}$ is uncorrelated with the size of the total error and that errors are uncorrelated across generations it is straightforward to show that any error in measuring parental permanent income will lead to a 
downward bias in the OLS estimate of $\beta$ and that this bias will be contingent on the amount of variance in the error components.

$$
p \lim \hat{\beta}=\beta \frac{\sigma_{y_{p}^{*}}^{2}}{\sigma_{y_{p}^{*}}^{2}+\sigma_{e_{p}}^{2}}
$$

Under these assumptions, errors in the dependent variable will have no impact on estimates of $\beta$.

In recent years the intergenerational mobility literature has begun to address sources of systematic bias, in particular lifecycle bias (Haider and Solon, 2006). Lifecycle bias is a consequence of the age at which incomes are measured. For example, if sons' earnings are measured before their career is established (and the returns to education are fully realised), the largest error will be found for those with the highest permanent income level. In this case, the correlation between the error and permanent income would lead to downward bias in the estimate of intergenerational income mobility $(\hat{\beta})$. In our data this downward bias is more likely to be greater in the later cohort (BCS) than the earlier cohort (NCDS) as earnings are measured in the BCS at age 30, compared to age 33 in the earlier cohort. In addition, the increasing trend in participation in higher education over this period could mean that younger cohorts are more likely to enter the labour market at an older age leading to a larger life-cycle bias. Given that the BCS cohort entered higher education in 1988, before the large expansion in higher education of the early 1990s, this is likely to be less of an issue here but will be important for younger generations. It is therefore hard to account for the observed rise in persistence as a consequence of lifecycle bias. If anything this should work in the opposite direction, attenuating the BCS cohort estimates.

Turning to other sources of non-classical measurement error, Gottschalk and Huynh (2010) have recently explored the consequences of reporting bias for within generation earnings mobility, and their results can be considered in the intergenerational context. As found by Bound et. al. (2001) mean reversion is common when reporting income, with those of higher income tending to under-report (negative errors) and with positive errors showing up among those with lower incomes. In the lifetime mobility context, where this type of error appears on both sides of the equation, a consequence of this mean reversion is that mobility is understated due to the correlation in errors within individuals. However Gottschalk and Huynh find that this tends to be offset by the attenuation bias generated by classical error. In the intergenerational context, we would imagine that errors are more weakly correlated across 
generations as the incomes are reported many years apart and by different agents. As a consequence we believe that classical measurement error is the dominant concern in this context.

Notice that with classical measurement error the partial correlation, $\hat{r}$, is affected in a different way from $\hat{\beta}$, because $\hat{r}$ is $\hat{\beta}$ multiplied by the ratio of the standard deviations of parents' to sons' income. As classical measurement error will tend to increase the estimated variance of the variable that it affects, any error in sons' earnings will lead to downward bias in $\hat{r}$ (but have no effect on $\hat{\beta}$ ). However, any error in parental income will have more of an impact on $\hat{\beta}$ compared to $\hat{r}$, as the standard deviation of parental income is in the numerator of the adjustment factor, and this will counteract the downward biasing effect on $\hat{\beta}$. This implies that it is necessary to have a good estimate of the standard deviation of sons' earnings (Black and Devereaux, 2010). Measurement error in sons' earnings will lead a larger estimated change in $\hat{r}$ compared to $\hat{\beta}$, the fact that we find similar estimated changes in both measures (as shown in Section 3.4 below) indicates that the divergent results are unlikely to be a result of errors in sons' earnings, and justifies our focus on exploring measurement error in parental income and devoting less space to the measurement of sons earnings.

\subsection{Applying the framework to the BHPS}

The cohort datasets only have comparable information on current parental income at age 16 meaning that we cannot directly measure permanent parental income in this data. We can, however, estimate permanent income in the British Household Panel Study (BHPS). This can be used to understand more about how current measured income and fathers' social class might be related to permanent income as described in equations (3) and (5).

The BHPS began in 1991 and now provides a long enough series of income data to allow us to calculate a close approximatation of permanent family income in childhood for the youngest sample members. We choose to use the derived net household income data as it provides the best comparison with the current income data in the cohort studies (Levy and Jenkins, 2008). The current income components are measured over the month prior to the annual interview or the most recent relevant period, except for employment earnings which are 'usual earnings'. We select 1206 two-parent families (to be comparable to our main cohort sample) with children under 16 who have more than seven income reports available. 
17 per cent of these have reported income in the full 15 years of the study while 65 per cent have income reports for 10 years or more. A 'permanent' childhood income measure is created by averaging across all observed current incomes. This can be compared with current income measured when the child is aged 16 or in the latest sweep available.

Alongside income, the BHPS includes information on fathers' social class and so we are able to predict the relationship between social class and income $\left(\hat{\delta}_{p} S C_{f}\right)$ from both (3) and (5) using both permanent childhood income and current income. We also have information on other household characteristics which will be related to permanent income and using these we can split $v_{p i}$ into the part that can be predicted $\left(\hat{\gamma}_{p} X_{p}\right)$ and a remainder. This remainder is a permanent unmeasured residual capturing any variance in permanent income not related to social class or our observable household characteristics We denote this element as $\hat{\varepsilon}_{p i}$.

$y_{p i}^{*}=\hat{\delta}_{p} S C_{f i}+\hat{\gamma}_{p} X_{p i}+\hat{\varepsilon}_{p i}$

Note that we apply a two-step approach here, first regressing family income on father's class and then regressing the remaining income residual on other household income characteristics. This allows fathers' class its maximum explanatory power. The characteristics $X_{p}$ in the BHPS are parental education, fathers' and mothers' employment status, age, housing tenure, region and self-reported financial difficulties. They are all measured in the most recent sweep at the same time as current income. They are chosen to capture as much of the remaining variation in permanent income as possible. Note that we do not require these predictors to be exogenous to income, our only requirement is that they are correlated with it. The same approach can also be used to decompose current income.

$$
y_{p i}=\hat{\lambda} S C_{f i}+\hat{\phi}_{p} X_{p i}+\hat{\varepsilon}_{p i}+\hat{e}_{p i}
$$

Notice that the extra term compared to equation (8) is the difference between current measured income and permanent income. Later we explore different components of this residual. The components associated with social class and other income proxies will differ from those estimated in equation (8), as they are based on current rather than permanent income and so the coefficients will differ. Our aim is to assess the difference in the share of the variance of permanent and current income that these measures capture to see if the components of current income are good proxies for permanent childhood income and its components. If successful, this approach can be used to identify permanent income variation in the cohort studies. 
Table 1A decomposes the variances of permanent and current income into the components described in the above equations. We estimate equations (8) and (9) in two stages, first regressing income (permanent and current) on class and then regressing the residual from this, within-class income, on to the other household income components. From these regressions we can predict the separate parts of income associated with class and with other income components before calculating the relative share of the total income variance attributable to each part. The first aspect to note is that the social class component captures less of the variance in permanent childhood income (15.7 per cent) than the part that is accounted for by the alternative income predictors (23.4 per cent). This is in spite of the fact that the alternative income predictors are only picking up variation in income within social class given our two-step approach. The majority of the variance in permanent childhood income is unexplained; $\hat{\varepsilon}_{p i}$ accounts for the remaining 61 per cent. The weak predictive power of social class and large permanent residual component is also found for current income.

Table 1B shows the correlations between the different estimated components of current and permanent childhood income predicted from our two-stage regression analysis. This once again illustrates the importance of residual permanent income $\left(\hat{\varepsilon}_{p i}\right)$ as this component of current income has the strongest correlation with our measure of permanent income. What is also apparent is that the correlation between current income and permanent childhood income is stronger than the correlation between permanent childhood income and the portion of current income predicted by fathers' social class (0.74 compared to 0.40$)$. In addition there is a very strong correlation $(0.83)$ between the permanent childhood income predicted by the Xs and the current income predicted by the Xs, indicating that we can legitimately make use of predictions based on long-term income predictors in our analysis using the cohort data where only current income is available.

Our results suggest that the relationship between current income and permanent childhood income is strong, and that current income does better as a proxy for permanent income than fathers' social class does. Other income predictors capture a large share of the variance of permanent income, certainly larger than social class. There remains a large residual permanent component of income which forms a substantial part of residual current income (that is, income which is orthogonal to social class and our other explanatory variables). The implication is that it is not correct to assume that all current income which cannot be predicted is simply noise in the data. 


\section{Mobility in the Cohort Studies}

\subsection{Data}

For the headline results on intergenerational mobility, both sociologists and economists have utilised the two publicly accessible mature British cohort studies: the British Cohort Study (BCS) of those born in 1970 and the National Child Development Study (NCDS) of those born in 1958. Both cohorts began with around 9000 baby boys included, although as we shall see the samples used are considerably smaller than this. The NCDS contains all children born in the UK in a week in 1958 and obtains detailed data at birth and ages 7, 11, 16, 23, 33, 42, 46 and most recently at 50. The BCS included all those born in Great Britain in a week in 1970 and was followed-up at ages 5, 10, 16, 30, 34 and 38.

Information on parental income is taken from the age 16 survey for both cohorts; it is only measured in both surveys at this point. In the NCDS parents were asked to place the father's earnings, the mother's earnings and other income into one of twelve categories. Family income is obtained by taking the adjusted midpoints (see Appendix B) of the three measures within their category and summing. In the BCS, parents are only asked about their total family income, and are asked to choose one of 11 categories. In addition to the difference between the 'single-question' income measure asked in the BCS and the components used to generate the NCDS income data, there are other differences in the types of income asked about in the two surveys.

We provide a Data Appendix B in the working paper version (Blanden et al. 2011) of this research to give details of the precise questions asked and adjustments made to move from the raw data to the variables used in our analysis. There is no evidence that the results are influenced by the adjustments we make to ensure comparability, or by the fact that the NCDS parental income was, for about 30 per cent of our sample, obtained during the period of the 1974 three-day week when working hours in many occupations were restricted due to a coal shortage. Information on the father's social class is obtained from the age 11 survey in the NCDS and the age 10 survey in the BCS, in line with those used to provide the headline results in sociology (Erikson and Goldthorpe, 2010). The schema used in both surveys is a 7category variable which is derived from the information on socio-economic group available in the datasets.

Adult earnings and sons' social class information is obtained at age 33 (NCDS) and 30 (BCS), where individuals are asked to provide information on their usual pay. This is a continuous gross measure for both cohorts which is then deflated using the relevant GDP 
deflator for the month of the interview. Although more recent earnings are available for both cohorts, we continue with the measures used in the original papers to keep the analysis consistent with Goldthorpe and Jackson (2007). Gregg and Macmillan (2012) present evidence which shows that the patterns presented here are observed at all ages so far available. A limitation of the data is that information on self-employment income is poor. Consequently, self-employed cohort members are dropped from our analysis. Sons' social class in the NCDS is measured at age 33 and is already available as a Goldthorpe schema. In the BCS there is no measure of the Goldthorpe schema at age 30 so the individuals' SOC90 occupational codes and employment status are recoded to the same schema used in the NCDS. We follow Goldthorpe and Jackson (2007) in creating our measures.

For the second stage of this paper, additional parental background variables are obtained at various points during the cohort member's childhood. This enables us to generate a matrix of $X_{p}$ variables as used in section 2.2, and similarly the adult surveys provide variables $X_{s}$ to predict sons' income. We use these to address the issue of measurement error directly. Our decomposition analysis provides a full discussion of the selection process for $X_{p}$ and $X_{s}$.

\subsection{Measures of Intergenerational Mobility using Income and Class}

Table 2 provides the headline results from the examination of intergenerational income mobility using the regression approach. These differ very slightly from those reported in Blanden, Gregg and Macmillan (2007) as age controls are not included (these are added later in section 4.1 equation (14) as one of the Xs used to predict differences in parental income in childhood in the cohorts). In the second panel we exclude families headed by single parents. We argue that this further selection is appropriate for this analysis given the focus on fathers' social class. These alterations do little to the change in $\hat{\beta}$, altering it from 0.086 in Blanden, Gregg and Macmillan (2007) to 0.070, and the change in $\hat{r}$ from 0.119 to 0.114 . The key finding remains extremely clear: intergenerational income mobility has fallen across the two birth cohort studies. Table 3 summarises measures of relative mobility from income and social class transition matrices. We group incomes in each generation into equal-sized categories (in this case quintiles) and document the relative odds of staying put compared to large movements. Likewise, relative social class mobility can also be summarised from transition matrices (see working paper, Blanden et al. (2011): tables 3 and 4 for full transition 
matrices and a discussion of absolute mobility. Further see Blanden (2011) for a discussion of absolute and relative class mobility distinctions). The results for income mobility reinforce the pattern shown in Table 2: there is a significant fall in mobility over time. The results for social class show that for both cohorts just over 30 per cent of children born into the two lowest social classes migrate to the top two as adults and likewise a constant 65 per cent of those born with fathers in the top two social classes remain in these classes as adults. A near constant 2:1 ratio of chances of entering the top two classes is revealed, indicating no change in relative mobility.

Notice that the results presented here do not allow for a direct comparison of the strength of the association in social class and income. We concentrate on trends only. In Erikson and Goldthorpe (2010) much is made of the stronger association across generations in social class compared to income. Their method for a direct comparison between the two is based on comparing income quintiles to a collapsed five rather than seven social class schema. However, this still does not provide the relevant comparison. By aggregating income into five quintiles much of the important variation which is used in calculating the betas and partial correlations has been lost. In the social class context, much less variation has been lost when the categories are collapsed slightly from seven to five; therefore we do not regard this as an informative comparison.

This preliminary exploration of income and class mobility suggests that simple crosstabulations reveal a growth in the association of income across the two cohorts while the strength of links in social class between generations remains quantitatively similar. This confirms the findings of Blanden, Goodman, Gregg and Machin (2004), Goldthorpe and Jackson (2007) and Erikson and Goldthorpe (2010).

\subsection{Samples}

Before digging deeper we must first check if differences in samples can explain the divergent results. The cross-tabulations for income and social class we have seen so far are not based on the same sample, and this alone could generate differences in the estimated trends. The last two columns of Table 3 repeat the results for relative social class for the income sample. There is some evidence of more long-range mobility from the bottom two into the top two social classes and less mobility from the top into the bottom. There is no evidence, however, that restricting the sample has affected the trend in intergenerational mobility by social class.

As has already been mentioned in section 3.1, the samples available for both analyses are substantially smaller than the initial samples of around 9,000 male cohort members. Even 
though we have shown that the difference in samples is not responsible for the different trends in mobility, attrition and item non-response could nonetheless be leading to a misleading perception of the change in mobility. In the Data Appendix B in the discussion paper Blanden et al. (2011) we spend some time documenting the impact of attrition on the samples in the NCDS and BCS and comment on the implications of this for the estimated change in mobility. While it is doubtless the case that these problems are substantial and do affect the representativeness of the samples used, as far as we can tell there is no evidence that these are responsible for the finding that UK income mobility fell between these cohorts.

\subsection{Data Quality}

As shown above in Section 2.1 classical measurement error in parental income will lead to attenuation in our parameters of interest. If more of the variance in parental income comes from error in the first cohort than the second, this could explain the differences in the results obtained by income and social class. Here we directly confront this possibility by considering a number of different strands of evidence. This enables us to evaluate the relative quality of the parental income data in the two cohorts.

The structure of the parental income questions is different between the cohorts; this could be a source of differential error. The parents of the NCDS cohort members provide banded information on three sources of income - fathers' earnings, mothers' earnings and other income; the mid-points are then summed together to create total parental income. In the BCS just one total band is provided. We might think that the difference in the structure of the questions would lead to more accurate income information in the NCDS (Micklewright and Schnef, 2010) or alternatively that a single banded total income measure may reduce the measured variance of income by more than one derived from three component sources of income. Further investigation of the data, its original form and quality, is included in the corresponding discussion paper (Blanden, Gregg and Macmillan, 2011), but is omitted here for reasons of brevity. We find that the choices we make in transforming the data are not responsible for the observed decline in mobility. Important features of the data, including the distribution of family income and the relationship between family income and fathers' social class, are also found to be very similar in the General Household Survey and Family Expenditure Survey collected at the same time.

As has already been mentioned, the parental income question in the NCDS was asked, in part, during the period of the three-day working week which occurred at the start of 1974 
as a result of industrial action in the coal industry. It is possible that the reported income is that of the three-day week rather than usual weekly income. If this is the case it could lead to unusually high measurement error in the first cohort and bias results towards finding a fall in mobility. In Blanden, Gregg and Macmillan (2011) we estimate the intergenerational coefficient and partial correlation in the NCDS for those families only interviewed in January and February 1974 (definitely within the three-day-week period). We find that, if anything, persistence is greater for those families for whom we would expect attenuation bias to be strongest. This is in line with Grawe's (2004) study who finds no evidence of income misreporting in the NCDS due to the reduced working week.

Another feature of measurement error is its impact on the two measures of intergenerational persistence $\hat{\beta}$ and $\hat{r}$. With classical measurement error in the explanatory variable $\hat{\beta}$ will be a downward biased estimate of the true parameter $\beta$. However, as $\hat{r}$ is estimated as $\hat{\beta}$ scaled by the relative variance of parental to sons' income, a larger variance in parental income will lead to a larger estimate of $\hat{r}$ relative to $\hat{\beta}$. In this case differential measurement error would manifest itself in a smaller rise in $\hat{r}$ across the cohorts compared to the rise in $\hat{\beta}$. Our results in Table 2 show a clear rise in both measures, with the partial correlation increasing slightly more than the elasticity.

\section{Alternative Hypotheses}

In this section, we return to the income components identified in Section 2 and show that the intergenerational income relationship can be decomposed into the intergenerational relationships between these components. Through this section we work up to an increasingly detailed decomposition. This framework enables us to generate a number of hypotheses which could explain the difference between the trends in income and social class mobility. The estimated decompositions reported in Sections 4.2 and 4.3 will enable us to comment on the plausibility of the different hypotheses.

\subsection{Expanding the Framework: A Decomposition Approach}

The measure of income mobility we use in the cohorts is the association between the current earnings of sons in their thirties and their parental income at age 16. Our decompositions are 
based on the partial correlation, although as we have seen, the trend for this measure is the same as for the intergenerational elasticity.

$$
\hat{r}=\frac{\operatorname{Cov}\left(y_{p_{i}}, y_{s_{i}}\right)}{\sqrt{\operatorname{Var}\left(y_{p_{i}}\right)} \sqrt{\operatorname{Var}\left(y_{s_{i}}\right)}}
$$

In section 2 we showed that current income can be decomposed into that part which is correlated with social class $\left(\lambda_{j} S C_{j i}, j\right.$ for generation), and a residual element. Part of this residual will be residual permanent income $\left(v_{j i}\right)$, and part will be the difference between permanent and measured current income $\left(e_{j i}\right)$. This implies that the numerator of equation(10) can be rewritten as:

$$
\begin{aligned}
& \operatorname{Cov}\left(y_{p i}, y_{s i}\right)=\operatorname{Cov}\left(\lambda_{p} S C_{p i}, \lambda_{s} S C_{s i}\right)+\operatorname{Cov}\left(v_{p i}+e_{p i}, \lambda_{s} S C_{s i}\right)+\operatorname{Cov}\left(v_{s i}+e_{s i}, \lambda_{p} S C_{p i}\right) \\
& +\operatorname{Cov}\left(v_{p i}+e_{p i}, v_{s i}+e_{s i}\right)
\end{aligned}
$$

One reason why results based on social class and income might vary is because trend in the covariance between those parts of income associated with social class differs from the trend in the direct association between social class across generations. This might be due to the changing role of mothers' earnings, as the strength of the association between parental income and social class (the $\lambda$ coefficients) will be dependent on which women work and how closely correlated parents' earnings are with each other. But there are other possible reasons for a divergence between $\operatorname{Cov}\left(\lambda_{p} S C_{p i}, \lambda_{s} S C_{s i}\right)$ and the association in social class across generations; the pattern requires empirical investigation.

To do this we follow the analysis performed on the BHPS and regress current income on social class in each birth cohort and for each generation $j$. This allows us to predict $\hat{\lambda}_{j} S C_{j i}$ from equation (9) and the equivalent for the sons' generation. The residual from the regression of income on social class is the sum of the estimated $v_{j i}$ and $e_{j i}$. By expanding the co-variances as suggested in equation (12) and scaling them by the denominator of equation (11) we can decompose $\hat{r}$ into four components: the intergenerational correlation of incomes associated with social class, the intergenerational association of residual incomes and their cross-correlations. The elements of the decomposition are listed as a matrix in equation (13). 


\begin{tabular}{|l|l|l|}
\hline & $\hat{\lambda}_{s} S C_{s i}$ & $\hat{v}_{s i}+\hat{e}_{s i}$ \\
\hline$\hat{\lambda}_{p} S C_{f i}$ & $\frac{\operatorname{Cov}\left(\hat{\lambda}_{p} S C_{p i}, \hat{\lambda}_{s} S C_{s i}\right)}{\sqrt{\operatorname{Var}\left(y_{p i}\right)} \sqrt{\operatorname{Var}\left(y_{s i}\right)}}$ & $\frac{\operatorname{Cov}\left(\hat{\lambda}_{p} S C_{p i}, \hat{v}_{s i}+\hat{e}_{s i}\right)}{\sqrt{\operatorname{Var}\left(y_{p i}\right)} \sqrt{\operatorname{Var}\left(y_{s i}\right)}}$ \\
\hline$\hat{v}_{p i}+\hat{e}_{p i}$ & $\frac{\operatorname{Cov}\left(\hat{v}_{p i}+\hat{e}_{p i}, \hat{\lambda}_{s} S C_{s i}\right)}{\sqrt{\operatorname{Var}\left(y_{p i}\right)} \sqrt{\operatorname{Var}\left(y_{s i}\right)}}$ & $\frac{\operatorname{Cov}\left(\hat{v}_{p i}+\hat{e}_{p i}, \hat{v}_{s i}+\hat{e}_{s i}\right)}{\sqrt{\operatorname{Var}\left(y_{p i}\right)} \sqrt{\operatorname{Var}\left(y_{s i}\right)}}$ \\
\hline
\end{tabular}

We start by exploring the element in the top-left hand corner of matrix (13). As discussed above, if this part shows a different pattern across cohorts from the trend in social class mobility then the social class predictions of income have changed their role across the cohorts. The upper right quadrant shows the contribution of the relationship between fathers' social class variation in income and within-class variation in sons' earnings. The lower half shows the relationships between within-class measured family income and sons' outcomes.

At this stage within-class income will contain both within-class permanent income and any deviation between measured current and permanent income. This latter term will include both measurement error and also any genuine transitory fluctuations in income. In order to begin to distinguish the role of measurement error we again follow the BHPS analysis and estimate $\hat{\phi}_{j} X_{j i}$ by regressing the residual from the regression of income on social class, $\hat{v}_{j i}$, on a set of $X s$.

$\hat{v}_{j i}=\hat{\phi}_{j} X_{j i}+\hat{\varepsilon}_{j i}+\hat{e}_{j i}$

Expanding the covariance matrix to take this into account enables a more detailed decomposition, the elements of which are given in equation (15).

\begin{tabular}{|l|l|l|l|}
\hline & $\hat{\lambda}_{s} S C_{s i}$ & $\hat{\phi}_{s} X_{s i}$ & $\hat{\varepsilon}_{s i}+\hat{e}_{s i}$ \\
\hline$\hat{\lambda}_{p} S C_{f i}$ & $\frac{\operatorname{Cov}\left(\hat{\lambda}_{p} S C_{p i}, \hat{\lambda}_{s} S C_{s i}\right)}{\sqrt{\operatorname{Var}\left(y_{p i}\right)} \sqrt{\operatorname{Var}\left(y_{s i}\right)}}$ & $\frac{\operatorname{Cov}\left(\hat{\lambda}_{p} S C_{p i}, \hat{\phi}_{s} X_{s i}\right)}{\sqrt{\operatorname{Var}\left(y_{p i}\right)} \sqrt{\operatorname{Var}\left(y_{s i}\right)}}$ & $\frac{\operatorname{Cov}\left(\hat{\lambda}_{p} S C_{p i}, \hat{\varepsilon}_{s i}+\hat{e}_{s i}\right)}{\sqrt{\operatorname{Var}\left(y_{p i}\right)} \sqrt{\operatorname{Var}\left(y_{s i}\right)}}$ \\
\hline$\hat{\phi}_{p} X_{p i}$ & $\frac{\operatorname{Cov}\left(\hat{\phi}_{p} X_{p i}, \hat{\lambda}_{s} S C_{s i}\right)}{\sqrt{\operatorname{Var}\left(y_{p i}\right)} \sqrt{\operatorname{Var}\left(y_{s i}\right)}}$ & $\frac{\operatorname{Cov}\left(\hat{\phi}_{p} X_{p i}, \hat{\phi}_{s} X_{s i}\right)}{\sqrt{\operatorname{Var}\left(y_{p i}\right)} \sqrt{\operatorname{Var}\left(y_{s i}\right)}}$ & $\frac{\operatorname{Cov}\left(\hat{\phi}_{p} X_{p i}, \hat{\varepsilon}_{s i}+\hat{e}_{s i}\right)}{\sqrt{\operatorname{Var}\left(y_{p i}\right)} \sqrt{\operatorname{Var}\left(y_{s i}\right)}}$ \\
\hline$\hat{\varepsilon}_{p i}+\hat{e}_{p i}$ & $\frac{\operatorname{Cov}\left(\hat{\varepsilon}_{p i}+\hat{e}_{p i}, \hat{\lambda}_{s} S C_{s i}\right)}{\sqrt{\operatorname{Var}\left(y_{p i}\right)} \sqrt{\operatorname{Var}\left(y_{s i}\right)}}$ & $\frac{\operatorname{Cov}\left(\hat{\varepsilon}_{p i}+\hat{e}_{p i}, \hat{\phi}_{s} X_{s i}\right)}{\sqrt{\operatorname{Var}\left(y_{p i}\right)} \sqrt{\operatorname{Var}\left(y_{s i}\right)}}$ & $\frac{\operatorname{Cov}\left(\hat{\varepsilon}_{p i}+\hat{e}_{p i}, \hat{\varepsilon}_{s i}+\hat{e}_{s i}\right)}{\sqrt{\operatorname{Var}\left(y_{p i}\right)} \sqrt{\operatorname{Var}\left(y_{s i}\right)}}$ \\
\hline
\end{tabular}


Note that the income predicted by a set of observable income proxies ( $\hat{\phi}_{p} X_{p i}$, for parents) will capture some of the within-class permanent income variation, but might also pick up variation in transitory income, to the extent that this can be predicted by Xs at a point in time. We attempt to distinguish the two below. What is important is that predicted income will be uncorrelated with random error, implying that if the elements in the middle row of equation (15) are higher in the BCS, the divergence in the income and social class is not driven by pure measurement error in parental income. However we must remember that $\hat{\phi}_{j} X_{j i}$ is not equivalent to $v_{j i}$, so a substantial element of permanent income variation will remain in the estimated residual.

Finally, we expand our framework to consider the role of transitory income, which has been highlighted by Erikson and Goldthorpe (2010) as a potential source of bias. The argument is that even if NCDS family income is measured just as accurately as it is in the BCS, the NCDS results might still be unreliable if the parental income measure is more transitory, and is therefore a poorer indicator of permanent family background. To test this hypothesis, we can expand our residual income term further to incorporate the transitory element of income. Note that there remains a pure 'error' component $(\eta)$ which means that measured income deviates from true income even at a point in time.

$$
\begin{aligned}
& y_{p i}=\lambda_{p} S C_{f i}+v_{p i}+u_{p i}+\eta_{p i} \\
& y_{s i}=\lambda_{s} S C_{s i}+v_{s i}+u_{s i}+\eta_{s i}
\end{aligned}
$$

With this expansion, is possible to enhance the decompositions to further distinguish permanent income from transitory income and evaluate its impact. We estimate this transitory component by dividing the characteristics, $X_{p i}$ into those considered more permanent characteristics $X_{p i}^{P}$ and those considered transitory $X_{p i}^{T}$. Note that permanent and transitory income which is orthogonal to the Xs, $\left(\hat{\varepsilon}_{p i}\right.$, and $\left.\hat{\varphi}_{p i}\right)$ will remain in the error term. The elements of this final decomposition are summarised in equation (18).

\begin{tabular}{|l|l|l|l|}
\hline & $\hat{\lambda}_{s} S C_{s i}$ & $\hat{\phi}_{s} X_{s i}$ & $\hat{\varepsilon}_{s i}+\hat{e}_{s i}$ \\
\hline$\hat{\lambda}_{p} S C_{f i}$ & $\frac{\operatorname{Cov}\left(\hat{\lambda}_{p} S C_{p i}, \hat{\lambda}_{s} S C_{s i}\right)}{\sqrt{\operatorname{Var}\left(y_{p i}\right)} \sqrt{\operatorname{Var}\left(y_{s i}\right)}}$ & $\frac{\operatorname{Cov}\left(\hat{\lambda}_{p} S C_{p i}, \hat{\phi}_{s} X_{s i}\right)}{\sqrt{\operatorname{Var}\left(y_{p i}\right)} \sqrt{\operatorname{Var}\left(y_{s i}\right)}}$ & $\frac{\operatorname{Cov}\left(\hat{\lambda}_{p} S C_{p i}, \hat{\varepsilon}_{s i}+\hat{e}_{s i}\right)}{\sqrt{\operatorname{Var}\left(y_{p i}\right)} \sqrt{\operatorname{Var}\left(y_{s i}\right)}}$ \\
\hline$\hat{\vartheta}_{p} X_{p i}^{P}$ & $\frac{\operatorname{Cov}\left(\hat{\phi}_{p} X_{p i}^{P}, \hat{\lambda}_{s} S C_{s i}\right)}{\sqrt{\operatorname{Var}\left(y_{p i}\right)} \sqrt{\operatorname{Var}\left(y_{s i}\right)}}$ & $\frac{\operatorname{Cov}\left(\hat{\phi}_{p} X_{p i}^{P}, \hat{\phi}_{s} X_{s i}\right)}{\sqrt{\operatorname{Var}\left(y_{p i}\right)} \sqrt{\operatorname{Var}\left(y_{s i}\right)}}$ & $\frac{\operatorname{Cov}\left(\hat{\phi}_{p} X_{p i}^{P}, \hat{\varepsilon}_{s i}+\hat{e}_{s i}\right)}{\sqrt{\operatorname{Var}\left(y_{p i}\right)} \sqrt{\operatorname{Var}\left(y_{s i}\right)}}$ \\
\hline
\end{tabular}




\begin{tabular}{|l|l|l|l|}
\hline$\hat{\vartheta}_{p} X_{p i}^{T}$ & $\frac{\operatorname{Cov}\left(\hat{\vartheta}_{p} X_{p i}^{T}, \hat{\lambda}_{s} S C_{s i}\right)}{\sqrt{\operatorname{Var}\left(y_{p i}\right)} \sqrt{\operatorname{Var}\left(y_{s i}\right)}}$ & $\frac{\operatorname{Cov}\left(\hat{\vartheta}_{p} X_{p i}^{T}, \hat{\phi}_{s} X_{s i}\right)}{\sqrt{\operatorname{Var}\left(y_{p i}\right)} \sqrt{\operatorname{Var}\left(y_{s i}\right)}}$ & $\frac{\operatorname{Cov}\left(\hat{\vartheta}_{p} X_{p i}^{T}, \hat{\varepsilon}_{s i}+\hat{\vartheta}_{s i}\right)}{\sqrt{\operatorname{Var}\left(y_{p i}\right) \sqrt{\operatorname{Var}\left(y_{s i}\right)}}}$ \\
\hline$\hat{\varepsilon}_{p i}+\hat{\varphi}_{p i}+\hat{\eta}_{p i}$ & $\frac{\operatorname{Cov}\left(\hat{\varepsilon}_{p i}+\hat{\varphi}_{p i}+\hat{\eta}_{p i}, \hat{\lambda}_{s} S C_{s i}\right)}{\sqrt{\operatorname{Var}\left(y_{p i}\right)} \sqrt{\operatorname{Var}\left(y_{s i}\right)}}$ & $\frac{\operatorname{Cov}\left(\hat{\varepsilon}_{p i}+\hat{\varphi}_{p i}+\hat{\eta}_{p i}, \hat{\phi}_{s} X_{s i}\right)}{\sqrt{\operatorname{Var}\left(y_{p i}\right)} \sqrt{\operatorname{Var}\left(y_{s i}\right)}}$ & $\frac{\operatorname{Cov}\left(\hat{\varepsilon}_{p i}+\hat{\varphi}_{p i}+\hat{\eta}_{p i}, \hat{\varepsilon}_{s i}+\hat{\vartheta}_{s i}\right)}{\sqrt{\operatorname{Var}\left(y_{p i}\right)} \sqrt{\operatorname{Var}\left(y_{s i}\right)}}$ \\
\hline
\end{tabular}

To summarise: the differences in the reported results for trends in income and social class mobility could be generated in the following ways, which will be indicated by different patterns in the estimated matrix (18).

1. The mapping from social class to income/earnings changed between the cohorts. This might occur as a consequence of changes in mothers' earnings. This will be apparent through a rise in the top left corner term of the above matrix, across the cohorts.

2. There is a greater degree of measurement error in the first cohort, the NCDS, which leads to larger attenuation bias understating intergenerational persistence in the cohort. This results in a misleading picture of rising persistence across the cohorts. This will be confined to the bottom row of the matrix but a rise here, across the cohorts, may be also driven by unmeasured permanent and transitory income.

3. The permanent income of parents that is unrelated to social class has a larger influence on sons' income in the second cohort (the BCS) compared with the first (the NCDS). This can be captured through a set of proxies for long-term income $\left(\hat{\phi}_{p} X_{p i}\right)$. This stronger permanent income transmission may also come through the parental residual permanent income $\left(\hat{\varepsilon}_{p i}\right)$, although this is not directly observable. This is captured in the second row.

4. Parental transitory income is larger in the first cohort compared with the second. This can be captured by the estimated portion of this, $\hat{\vartheta}_{p} X_{p i}^{T}$ but may also come about because there is more residual transitory income in the within-class income not captured by income proxies. This will generate attenuation bias if transitory income changes have zero or very small correlations with sons' outcomes and will appear in the third row.

\subsection{Decomposing Persistence by the Components of Income}


The first explanation for the differences in results for trends in social class and income mobility is that the association between $\lambda_{p} S C_{f i}$ and $\lambda_{s} S C_{s i}$ increased across the cohorts even though the relationship between social class is constant.

Table 4 estimates matrix (13) for the two cohorts and decomposes $\hat{r}$ into four parts: the correlation across individuals of permanent income/earnings predicted by social class, the correlation of residual income (residual permanent and transitory income plus measurement error) and their cross-correlations. The cells sum to the total partial correlation. There is very little change in the correlation of incomes/earnings associated with social class as shown in the top left-hand corner of the matrix for each cohort. Indeed this element of persistence has reduced slightly. We therefore reject hypothesis 1 . Mobility as captured by social class and income predicted by social class tell the same story of no change across the cohorts.

Table 4 also allows us to explore the relationship between fathers' income associated with social class and sons' residual earnings. This element of persistence has increased from 0.01 to 0.04 suggesting that there is a contribution to the difference in mobility from an increased relationship between income associated with fathers' social class and the sons' earnings, but that this does not come through sons' social class. Combined, the results show that the larger part of the difference in the results between income and social class must be generated by the relationship between sons' earnings and the other elements of parental income.

Following equation (15) we further decompose measured income/earnings, picking out the part of income that is associated with characteristics other than social class in each generation. The $X$ s used to predict parental income are those shown to have a strong correlation with income in the BHPS as shown in Section 2. Additional information available in the cohorts is also added including information on lone parenthood at birth, five and 16 (our sample is restricted to two-parent families only in the last observed measure in the BHPS and therefore lone parenthood is not available in this study) and free school meal (FSM) receipt at age 10 (FSM status is not available in the BHPS).

Table 5 summarises the relationship between current income and the available $X \mathrm{~s}$ in the BHPS and in the cohorts. The full regression results for the cohorts are reported in Blanden, Gregg and Macmillan (2011) Appendix A. The R-squareds for residual income on these characteristics are around 0.3 in both the NCDS and the BCS (this contrasts with the difference in these for the regression of parental income on social class, as we have seen). This contradicts the hypothesis of differential data quality. 
The $X$ s used to predict sons' earnings include detailed education measures, information on early labour market attachment and variables on housing tenure, car ownership and pension contribution. Results from these regressions are also shown in the working paper.

Table 6 reports the results from using predicted income from these regressions to expand the decomposition. The results show that all of the elements of sons' income are more strongly correlated with $\hat{\phi}_{p} X_{p i}$ in the second cohort compared with the first. We can be confident that this component is not generated by differential measurement error. As shown in the Notes to this Table, the overall increase in the partial correlation associated with this predicted part of permanent income provides 0.052 points or 46 per cent of the total rise.

In total, 0.067 points or 59 per cent of the total observed increase in income persistence can be accounted for as due to income associated with fathers' social class $(0.015$ point increase) or other parental characteristics (0.052 points increase). We can think of this as a lower bound estimate of the true change in persistence, as it assumes that the change in persistence associated with the residual permanent income $\hat{\varepsilon}_{p i}$ and unmeasured transitory income is zero. We relax this assumption below.

\subsection{The Role of Transitory Income}

Blanden et al (2004) use the New Earnings Survey (NES) to calculate the proportion of variance in earnings over a five year period that could be regarded as 'permanent' for men in the years around the age 16 income measures. In that paper we find that in the years around 1986, men's transitory fluctuations account for 21 per cent of the variance in any year, while around 1974 this was 32 per cent. It appears that there is some evidence to point towards greater transitory income in the time period of first cohort, a view supported by Dickens (2000). Erikson and Goldthorpe (2010) note that if allowance were made for this problem, the fall in mobility would 'no longer appear as dramatic as it does when the data are taken at face value'. Applying the same figures to parental income, transitory error of this magnitude would imply a true $\beta$ of .321 in the NCDS and .366 in the BCS, reducing the change in beta to 0.045 , compared to the 0.07 found in Table 2 .

There are three points that need to be made about this evidence. First, that this reduced figure is still a statistically significant rise and, at about $60 \%$ of the observed figure, is broadly in line with the lower bound estimate given at the end of the previous subsection. Secondly, the NES calculations are for individual earnings, whereas we need to know about 
transitory error in family income, including the impact of mothers' earnings and other income. Third, this assumes that income shocks have no effect on children's outcomes and are thus the same as measurement error. There is a large body of evidence to suggest that this is not the case. Mayer (1998), Blanden and Gregg (2004) and Tominey (2010) (looking at income changes) and Oreopolous et al. (2008) and Gregg et al. (2012) (focusing on father's job loss) show that shocks to parental income do influence children's outcomes, although not to the same extent as differences in permanent income. Transitory income should not be thought of as simply another form of measurement error. However, given our focus on permanent income, we try to uncover the implications of excluding the influence of transitory income from our mobility estimates.

To provide some direct evidence on the importance of transitory income we return to the decomposition framework. So far, our decomposition analysis has shown that the relationship between predicted parental income and sons' earnings increased between the cohorts. However, this will be predicting some elements of transitory income alongside permanent income. In this case we cannot safely rule out the hypothesis that the results are being generated by a larger amount of predictable transitory income in the first cohort, if this has a weak relationship with sons' outcomes.

To assess this, we divide our predicting characteristics into two groups. To assist with the classification, Table 7 shows the correlations between income predicted by the various Xs and the permanent (average) and transitory (current less average) income in the BHPS. We select as permanent Xs those factors which are clearly more strongly correlated with permanent income, such as education. We also include in the permanent group any timevarying factors which are measured in the cohorts before age 16 when income is measured, as their predictive power must come from their correlation with long-term differences in living standards. An example of such a characteristic is the housing tenure of the parents five (six) years before income is measured in the NCDS (BCS) (when the child is aged 11/10). The key distinction therefore between time-varying factors into the permanent and transitory predictors is the timing of the measure. We use as transitory predictors housing tenure, lone parent status, region and employment status measured at age 16, the time the income variable is obtained. When conditioned on earlier measures of the same variable these will provide a good indicator of transitory income shocks. For example, the father not working at 16 given their employment status at 10 will predict the income associated with changes in the father's employment status. 
Table 8 repeats the decomposition, separating out the influence of predicted transitory income as described by equation (18). The results from this exercise indicate that transitory income is unlikely to be driving the difference in results, although as expected the transitory component is correlated with sons' earnings, and this association increases slightly across the cohorts. The increase in the partial correlation in the permanent predicted part is 0.048 , just a slight reduction on the 0.052 increase observed in Table 6. Taking the predicted rise in income persistence from social class and the observable permanent characteristics gives a combined increase in persistence of 0.063 out of the total 0.114 rise observed overall, or 55 per cent of the total. Once again this is a lower bound, assuming no change in the relationship between permanent residual parental income and sons' earnings.

An alternative approach allows us to put an upper bound on this quantity by applying some of our knowledge about residual permanent income in the BHPS to the cohorts. We know that the magnitudes of the different components of the final column of the decompositions will be dependent on the share of the variance of income accounted for by each. Table 5 compares the share of the variance in current parental income that is attributable to social class, other characteristics and the residual. Broadly, the cohorts seem quite similar to the BHPS. Based on these results we can make the assumption that in the cohorts, as in the BHPS, the variance of the permanent residual component is twice the magnitude of the $\hat{\phi}_{p} X_{p i}$ part. Using an Oaxaca-style decomposition, where $S_{\varepsilon c}$ is the share of permanent income accounted for by $\varepsilon$ in cohort $c$ and $R_{c}$ is the ratio which transforms the beta into the partial correlation (see Table 2) we can show that:

$$
\begin{aligned}
& \frac{\operatorname{Cov}\left(\varepsilon_{p i}, y_{s i}\right)_{70}}{\operatorname{Var}\left(\varepsilon_{p i}\right)_{70}} S_{\varepsilon 70} R_{70}-\frac{\operatorname{Cov}\left(\varepsilon_{p i}, y_{s i}\right)_{58}}{\operatorname{Var}\left(\varepsilon_{p i}\right)_{58}} S_{\varepsilon 58} R_{58}= \\
& \left(\frac{\operatorname{Cov}\left(\varepsilon_{p i}, y_{s i}\right)_{70}}{\operatorname{Var}\left(\varepsilon_{p i}\right)_{70}}-\frac{\operatorname{Cov}\left(\varepsilon_{p i}, y_{s i}\right)_{58}}{\operatorname{Var}\left(\varepsilon_{p i}\right)_{58}}\right) S_{\varepsilon 58} R_{58}+\frac{\operatorname{Cov}\left(\varepsilon_{p i}, y_{s i}\right)_{70}}{\operatorname{Var}\left(\varepsilon_{p i}\right)_{70}}\left(S_{\varepsilon 70} R_{70}-S_{\varepsilon 58} R_{58}\right)
\end{aligned}
$$

We assume that the shares of permanent income from $\varepsilon_{p i}\left(S_{\varepsilon 70}\right.$ and $\left.S_{\varepsilon 58}\right)$ do not change and are set to the level in the BHPS, and that the multiplying ratios are constant across the cohorts so the second term drops out (in fact $R_{70}>R_{58}$ so the second term will likely also add a small amount to the upper bound.) Setting the change in the persistence of $\varepsilon_{p i}$ across the cohorts equal to that of $\hat{\phi}_{p} X_{p i}$ means that the 0.048 change is doubled to make 0.096 (because the share of permanent income associated with $\varepsilon_{p i}$ is twice that associated with $\hat{\phi}_{p} X_{p i}$ ). If this is 
added to our lower bound of 0.063 the expected change is 0.159 . This is actually larger than the real change and suggests that in reality either the share of residual permanent income in the 1958 cohort may be lower than in the BHPS, and/or persistence in this component has risen less strongly than persistence in predicted permanent income. However, this thought experiment shows that it is easy to explain the changes we do find using this approach. The upper and lower bound estimates based on assessments of permanent income straddle the observed rise in intergenerational persistence and clearly indicate that permanent income mobility declined across the cohorts.

\section{Discussion and Conclusion}

This paper extends a framework first set out by Björklund and Jäntti (2000) to model the link between social class and income measures of intergenerational mobility. We take as our baseline model the relationship between the permanent income of parents and the permanent income of sons. Using a framework that relates permanent income to social class and current income, we are able to offer four possible explanations for the divergence between trends in intergenerational mobility in income and social class in the UK. Here we will briefly review the evidence for each hypothesis in turn, drawing out the broader implications of our results for the study of mobility.

First we produce a number of pieces of evidence which counter the claim that poorer quality parental income data in the first cohort is the primary explanation for the apparent increase in income mobility. This is confirmed in our later analysis with clear evidence of a rise in intergenerational mobility in income predicted by observable characteristics, which are free from the influence of measurement error. Hence the hypothesis of differential measurement error is rejected.

Using a framework relating current and permanent income to social class and other measured characteristics enables us to explore alternative explanations for the divergent results. It is possible that the relationship between fathers' social class and family income has changed, perhaps owing to changes in the importance of mothers' earnings for family income. This could lead to a divergence between the intergenerational correlations in social class and intergenerational persistence in income associated with social class. This turns out not to be important over this period, perhaps because this data predates the large rise in mothers' employment and lone parenthood which occurred from the mid-1980s to the late 1990s. However, our framework has drawn attention to the potential importance of this issue 
for more recent cohorts of children, for whom the male breadwinner premise is less and less appropriate. This section of the analysis also found that differences in income associated with fathers' social class are having a greater influence on sons' (within social class) earnings in the second cohort. This accounts for 13 per cent of the observed rise in intergenerational income persistence.

The third hypothesis which would explain the divergence is that the trend in the persistence in permanent income within fathers' social class groups differs from the trend in persistence in income that is predicted by fathers' social class. This is plausible given that analysis of BHPS data reveals social class is a rather poor predictor of permanent childhood income. This hypothesis can be explored by looking at income predicted by other proxies, such as parental education, early lone-parenthood and housing tenure. Our investigations find that around 46 per cent of the headline rise in intergenerational income mobility is accounted for by income predicted by other characteristics. It appears that this component of permanent income has an increasing impact on the outcomes of the next generation. Taken together with the increased importance of fathers' social class in predicting sons' earnings above, 59 per cent of the total rise is explained.

A further possibility is that the magnitude of the transitory component of income is greater in the first cohort. Erikson and Goldthorpe (2010) focus on transitory variations in income as the most likely source of bias in the income mobility results and imply that social class is a more stable measure. We seek to capture transitory income variation by predicting income based on characteristics at age 16 that have changed since age 10. Our investigations show that measurable transitory income is responsible for only a small fraction of the observed changes in persistence.

Our decomposition approach to account for transitory income variation indicates that around 43 per cent of the rise in intergenerational persistence is associated with within-class permanent income and nine per cent with the increased importance of transitory parental income on sons' outcomes. This still leaves a large element unexplained, but enables us to provide an upper and lower bound on how much of the change in intergenerational persistence is genuine. The lower bound treats the entire unexplained rise as measurement error and says that the true rise is a statistically significant 6.6 points rather than the observed 11.4. This, however, ignores that in the BHPS these predictors account for only about 40 per cent of permanent family income differences. If the rest of permanent family income variation behaved in the same way as the observed permanent income then the headine rise 
in persistence across generations would be exceeded, leading to the conclusion that the observed pattern is highly plausible.

Income inequality rose strongly through the 1980s (see Brewer et al. 2008, for a recent summary), and in a companion paper, Blanden (2011) finds a strong association between intergenerational income persistence and cross-sectional income inequality based on international comparisons. It seems plausible that the divergence of trends in intergenerational mobility for income and social class in the UK is related to the growth in within-class income inequality over the same period. It should be noted, however, that evidence from the US is very unclear as to whether increasing income inequality there has occurred primarily between social class groups or within them (Weeden et al, 2007, and Kim and Sakamoto, 2008). There is no comparable evidence for the UK and it is an area that requires future research.

Intergenerational income and social class mobility capture different things. Social class reflects job autonomy and wider social capital while income and earnings reflect economic opportunities. In this study we find limited common ground between the two approaches. We show that social class is a poor proxy for permanent income, and that there are good reasons why the trends for economic and social mobility differ for those growing up in 1970s and 1980s Britain, as inequality rose. 


\section{References}

Aaronson, D. and Mazumder, B. (2008) Intergenerational Economic Mobilty in the US: 1940-2000. J Human Resources, 43, 139-172.

Björklund, A. and Jäntti, M. (2000) Intergenerational mobility of socio-economic status in comparative perspective. Nordic Journal of Political Economy, 26, 3-33.

Björklund, A. and Jäntti, M. (2009) Intergenerational mobility and the role of family background. In The Oxford Handbook of Economic Inequality (eds W. Salverda, B. Nolan and T. Smeeding). Oxford: Oxford University Press.

Black, S. and Devereux, P. (2010) Recent Developments in Intergenerational Mobility. In The Handbook of Labor Economics (eds O. Ashenfelter and D. Card). Amersterdam: North Holland.

Blanden, J. and Gregg, P. (2004) Family Income and Educational Attainment: A Review of Approaches and Evidence for Britain. Oxford Review of Economic Policy Special Issue on Education, 20, 245-263.

Blanden, J., P. Gregg and Macmillan, L. (2007) Accounting for Intergenerational Income Persistence: Noncognitive Skills, Ability and Education. Economic Journal, 117, C43-C60.

Blanden, J., P. Gregg and Macmillan, L. (2011) Intergenerational Persistence in Income and Social Class: The Impact of Within-Group Inequality. IZA Discussion Paper No. 6202.

Blanden, J. (2010) Social Mobility: Concepts and Measurement. In Options for Britain II: Cross Cutting Policy Issues - Changes and Challenges (eds V. Uberoi, A. Coutts, D. Halpern, and I. McLean). Wiley-Blackwell in association with The Political Quarterly.

Blanden, J. (2011) Cross-country rankings in intergenerational mobility: a comparisons of approaches from economics and sociology. Forthcoming J. Economic Surveys.

Blanden, J, Goodman, A., Gregg, P. and Machin, S. (2004) Changes in intergenerational mobility in Britain. In Generational Income Mobility in North America and Europe. (ed M. Corak). Cambridge: Cambridge University Press.

Blau, P. M. and Duncan, O. D. (1967) The American Occupational Structure. New York: Wiley.

Bound, J. Brown, C. and Mathiowitz, N. (2001) Measurement error in survey data. In Handbook of Econometrics (eds J.Heckman, and E. Leamer). New York: Elsevier Science.

Breen, R. (2004) Social Mobility in Europe. Oxford: Oxford University Press.

Brewer, M. Muriel, A. Phillips, D. and Sibieta, L. (2008) Poverty and Inequality in the UK. IFS Commentaries C105.

Corak, M. (2006) Do poor children become poor adults? Lessons for public policy from a cross country comparison of generational earnings mobility. In Research on Economic Inequality Vol 13: Dynamics of Inequality and Poverty (eds J. Creedy and G. Kalb). Amsterdam: Elsevier Press.

Dickens, R. (2000) The Evolution of Individual Male Earnings in Great Britain 1975-95. Economic Journal, 110, 27-49. 
Erikson, R. and Goldthorpe, J. H. (1992) The Constant Flux - A Study of Class Mobility in Industrial Societies. Oxford: Clarendon.

Erikson R. and J. H. Goldthorpe, (2010) Has social mobility in Britain decreased? Reconciling divergent findings on income and class mobility. British Journal of Sociology, 61, 211-230.

Goldthorpe, J. H. (2000) On Sociology: Numbers, Narratives and the Integration of Research and Theory. Oxford: Oxford University Press.

Goldthorpe, J. H. and Jackson, M. (2007) Intergenerational Class Mobility in Contemporary Britain: Political Concerns and Empirical Findings. British Journal of Sociology, 58, 525-546.

Goldthorpe, J. and McKnight, A. (2006) The Economic Basis of Social Class. In Mobility and Inequality: Frontiers of Research in Economics and Sociology (eds S. Morgan, D. Grusky and G. Fields). Stanford: Stanford University Press.

Gottschalk, P. and Huynh, M. (2010) Are earnings inequality and mobility overstated? The impact of non-classical measurement error. Review of Economics and Statistics, 92, 302-315.

Grawe, N. (2004) The 3-day week of 1974 and earnings data reliability in the Family Expenditure Survey and the National Child Development Survey. Oxford Bulletin of Economics and Statistics, 66(3), 567-579.

Gregg, P., Macmillan, L. and Nasim, B. (2012) The Impact of Fathers' Job Loss during the 1980s Recession on their Child's Educational Attainment. forthcoming Fiscal Studies.

Gregg, P. and Macmillan, L. (2012) Updating the evidence; the role of life-cycle bias, measurement error and non-working incomes in the story of intergenerational mobility in the UK. mimeo

Grusky, D. and Weeden, K. (2001) Decomposition without death: A research agenda for a new class analysis. Acta Sociologica, 44(3), 203-218.

Haider, S. and Solon, G. (2006) Life-cycle Variation in the Association between Current and Lifetime Earnings. American Economic Review, 96, 1308-1320.

Kim, C-H, and Sakamoto, A. (2008) The Rise of Intra-Occupational Wage Inequality in the United States, 1983-2002. American Sociological Review, 72, 129-157.

Lee, C. and Solon, G. (2009) Trends in Intergenerational Income Mobility. The Review of Economic and Statistics, 91(4), 766-772.

Levy, H and Jenkins, S. P. (2008) Documentation for Derived Current and Annual Net Household Income Variables, BHPS waves 1-16. UK Data Archive.

Mayer, S. (1998) What Money Can't Buy. Family Income and Children's Life Chances. Cambridge: Harvard University Press.

McIntosh, J. and Munk, M. (2009) Social class, family background, and intergenerational mobility. European Economic Review, 53, 107-117.

Micklewright, J. and Schnef, S. (2010) How reliable are income data collected from a single question? J. Royal Statistical Society: Series A (Statistics in Society), 173, 409-429.

Oreopoulos, P, Page, M. and Huff- Stevens, A. (2008), The intergenerational effects of worker displacement. J. Labor Economics, 26, 455- 483.

Saunders, P. (2010) Social Mobility Myths. London: Civitas. 
Solon, G. (1992) Intergenerational Income Mobility in the United States. American Economic Review, 82, 393-408.

Solon, G. (1999), Intergenerational mobility in the labor market. In Handbook of Labor Economics (eds O. Ashenfelter and D. Card), vol. 3A, Amsterdam: North-Holland.

Tominey, E. (2010) The Timing of Parental Incomes and Child Outcomes: The Role of Permanent and Transitory Shocks. IZA Discussion Paper No. 5225.

Weeden, K. Kim, Y.-M., Di Carlo, M. and Grusky, D. (2007) Social Class and Earnings Inequality. American Behavioural Scientist, 50, 702-736. 
Table 1A: Components of Permanent Childhood and Current Income in the BHPS

\begin{tabular}{lc}
\hline & $\begin{array}{c}\text { \% share of } \\
\text { variance }\end{array}$ \\
\hline Permanent childhood income, components associated with: & \\
Fathers' social class $\left(\hat{\delta}_{p} S C_{f i}\right)$ & 15.67 \\
Other income predictors $\left(\hat{\gamma}_{p} X_{p i}\right)$ & 23.38 \\
Residual permanent income $\left(\hat{\varepsilon}_{p i}\right)$ & 60.96 \\
Current childhood income, components associated with: & \\
Fathers' social class $\left(\hat{\lambda}_{p} S C_{f i}\right)$ & 7.53 \\
Other income predictors $\left(\hat{\phi}_{p} X_{p i}\right)$ & 18.48 \\
Residual permanent income $\left(\hat{\varepsilon}_{p i}\right)$ & 39.76 \\
Error $\left(\hat{e}_{p i}\right)$ & 34.22 \\
\hline
\end{tabular}

Note: This methodology has been replicated using the father's modal social class instead as measured social class changes across time and therefore may also not be permanent. As expected this measure accounts for a larger percentage share of the variation in permanent income ( 25 per cent as opposed to 16 per cent) suggesting that class measured at a single point in time has limitations as a measure of 'permanent class'.

Table 1B: Correlation matrix between components of income in BHPS

\begin{tabular}{lcccc}
\hline $\begin{array}{l}\text { Current income } \\
\text { components }\end{array}$ & $\begin{array}{l}\text { Permanent income components } \\
\text { Total } \\
\text { permanent } \\
\text { income }\end{array}$ & $\begin{array}{l}\text { Fathers'social } \\
\text { class } \\
\left(\hat{\delta}_{p} S C_{f i}\right)\end{array}$ & $\begin{array}{l}\text { Other income } \\
\text { predictors } \\
\left(\hat{\gamma}_{p} X_{p i}\right)\end{array}$ & $\begin{array}{l}\text { Residual } \\
\text { permanent } \\
\text { income }\left(\hat{\varepsilon}_{p i}\right)\end{array}$ \\
$\begin{array}{l}\text { Total current income } \\
\text { Fathers' social class }\end{array}$ & 0.735 & 0.294 & 0.446 & 0.539 \\
$\left(\hat{\lambda}_{p} S C_{f i}\right)$ & 0.398 & 0.951 & 0.347 & -0.152 \\
$\begin{array}{l}\text { Other income } \\
\text { predictors }\left(\hat{\phi}_{p} X_{p i}\right)\end{array}$ & 0.525 & 0.338 & 0.832 & 0.000 \\
$\begin{array}{l}\text { Residual permanent } \\
\text { income }\left(\hat{\varepsilon}_{p i}\right)\end{array}$ & 0.707 & -0.160 & 0.000 & 1.000 \\
Error $\left(\hat{e}_{p i}\right)$ & -0.007 & -0.001 & 0.000 & -0.009 \\
\hline
\end{tabular}

Notes:

1. $\mathrm{N}=1206$

2. Other income characteristics; parental education, parental age, parental employment, housing tenure, self reported financial difficulties and region, all from the last observed period

3. Fathers' Social class is from last observed period

4. Permanent income measured as an average of all income observations across time; min annual obs=7 max annual obs $=16,30 \% 14$ obs or more, $65 \% 10$ obs or more.

5. Current income is from the last data point available for the family. 
Table 2: Changes in Intergenerational Mobility using Family Income at age 16 and Sons' Earnings (at age 33 NCDS and 30 BCS): Elasticities and Partial Correlations

\begin{tabular}{llll}
\hline & NCDS & BCS & Difference \\
\hline$\hat{\beta}$ & $0.211(.026)$ & $0.278(.021)$ & $0.067(.034)$ \\
Partial correlation $(\hat{r})$ & $0.172(.021)$ & $0.280(.022)$ & $0.107(.030)$ \\
\hline $\mathbf{N}$ & 2163 & 1976 & \\
\hline $\begin{array}{l}\text { Cohort members living } \\
\text { with both parents }\end{array}$ & NCDS & BCS & Difference \\
\hline$\hat{\beta}$ & $0.219(.027)$ & $0.289(.022)$ & $0.070(.034)$ \\
Partial correlation $(\hat{r})$ & $0.176(.021)$ & $0.290(.022)$ & $0.114(.031)$ \\
\hline $\mathbf{N}$ & 2109 & 1932 & \\
\hline
\end{tabular}

Notes:

1. These figures differ very slightly from those Blanden, Gregg and Macmillan (2007) table 4 because parental age controls are not included.

2. Standard errors are in parentheses. 
Table 3: Summary statistics of changes in relative class mobility across cohorts and samples

\begin{tabular}{|c|c|c|c|c|c|c|c|}
\hline \multirow[t]{3}{*}{ Income measures } & \multicolumn{5}{|c|}{ Social class measures } & & \\
\hline & \multicolumn{2}{|c|}{$\begin{array}{l}\text { Income sample } \\
\text { (Cohort } \\
\text { members living } \\
\text { with both } \\
\text { parents) } \\
\end{array}$} & & \multicolumn{2}{|c|}{$\begin{array}{l}\text { Social class } \\
\text { sample }\end{array}$} & \multicolumn{2}{|c|}{$\begin{array}{l}\text { Income sample } \\
\text { (Cohort members } \\
\text { living with both } \\
\text { parents) }\end{array}$} \\
\hline & NCDS & BCS & & NCDS & BCS & NCDS & BCS \\
\hline $\begin{array}{l}\text { Proportion of those in top income } \\
\text { quintile remaining there }\end{array}$ & $30 \%$ & $37 \%$ & $\begin{array}{l}\text { Proportion of those in top two origin } \\
\text { social classes remaining there }\end{array}$ & $63 \%$ & $65 \%$ & $68 \%$ & $67 \%$ \\
\hline $\begin{array}{l}\text { Proportion of those in bottom } \\
\text { income quintile moving to the } \\
\text { top }\end{array}$ & $13 \%$ & $11 \%$ & $\begin{array}{l}\text { Proportion of those in bottom two } \\
\text { origin social classes moving to the } \\
\text { top two }\end{array}$ & $31 \%$ & $32 \%$ & $35 \%$ & $35 \%$ \\
\hline Relative odds & 2.39 & 3.19 & Relative odds & 2.04 & 2.02 & 1.95 & 1.94 \\
\hline $\begin{array}{l}\text { Proportion of those in bottom } \\
\text { income quintile remaining there }\end{array}$ & $27 \%$ & $34 \%$ & $\begin{array}{l}\text { Proportion of those in bottom two } \\
\text { origin social classes remaining there }\end{array}$ & $51 \%$ & $38 \%$ & $48 \%$ & $40 \%$ \\
\hline $\begin{array}{l}\text { Proportion of those in top income } \\
\text { quintile moving to the bottom }\end{array}$ & $12 \%$ & $8 \%$ & $\begin{array}{l}\text { Proportion of those in top two origin } \\
\text { social classes moving to the bottom } \\
\text { two }\end{array}$ & $21 \%$ & $13 \%$ & $16 \%$ & $13 \%$ \\
\hline Relative odds & 2.32 & 3.97 & Relative odds & 2.45 & 2.78 & 3.02 & 2.95 \\
\hline
\end{tabular}

Notes:

1. Sample sizes for income measures; $\mathrm{N}=2109$ in the NCDS and N=1932 in the BCS for income sample

2. Sample sizes for social class measures; $N=3,858$ in the NCDS and N=3,810 in the BCS for the social class sample.

3. Sample sizes for social class measures; $\mathrm{N}=1,729$ in the NCDS and N=1,646 in the BCS for income sample with no lone parents. (Note this differs from 1 as fathers' social class is missing for some families where income is reported).

4. The restriction to no lone parents makes almost no difference to these statistics as only very few of those we define as lone parents have information on social class. 
Table 4: Decomposition of Income Mobility Changes - Social class only

\begin{tabular}{llll}
\hline NCDS & $\hat{\lambda}_{s} S C_{s i}$ & $\hat{v}_{s i}+\hat{e}_{s i}$ & Total \\
$\hat{\lambda}_{p} S C_{f i}$ & 0.068 & 0.010 & $\mathbf{0 . 0 7 8}$ \\
$\hat{v}_{p i}+\hat{e}_{p i}$ & -0.006 & 0.103 & $\mathbf{0 . 0 9 7}$ \\
Total & $\mathbf{0 . 0 6 2}$ & $\mathbf{0 . 1 1 4}$ & $\mathbf{0 . 1 7 6}$ \\
\hline BCS & $\hat{\lambda}_{s} S C_{s i}$ & $\hat{v}_{s i}+\hat{e}_{s i}$ & Total \\
$\hat{\lambda}_{p} S C_{f i}$ & 0.054 & 0.039 & $\mathbf{0 . 0 9 3}$ \\
$\hat{v}_{p i}+\hat{e}_{p i}$ & 0.066 & 0.130 & $\mathbf{0 . 1 9 7}$ \\
Total & $\mathbf{0 . 1 2 0}$ & $\mathbf{0 . 1 7 0}$ & $\mathbf{0 . 2 9 0}$ \\
\hline
\end{tabular}

Notes:

1. Sample sizes 2,109 and 1,932

2. Notation refers to notation in text

3. Each cell represents a covariance scaled by the total variance as illustrated in equation (14)

Table 5: Decomposition of Parental Income Variance: NCDS, BCS and BHPS cohorts

\begin{tabular}{|c|c|c|c|c|}
\hline NCDS current income & $y_{p}$ & $\hat{\lambda}_{p} S C_{f i}$ & $\hat{\phi}_{p} X_{p i}$ & $\hat{\varepsilon}_{p i}+\hat{e}_{p i}$ \\
\hline \multirow{2}{*}{$\begin{array}{l}\text { Variance } \\
\text { Percentage of total } \\
\text { variance }\end{array}$} & 0.1381 & 0.0115 & 0.0435 & 0.0830 \\
\hline & & 8.36 & 31.53 & 60.11 \\
\hline BCS current income & $y_{p}$ & $\hat{\lambda}_{p} S C_{f i}$ & $\hat{\phi}_{p} X_{p i}$ & $\hat{\varepsilon}_{p i}+\hat{e}_{p i}$ \\
\hline \multirow{2}{*}{$\begin{array}{l}\text { Variance } \\
\text { Percentage of total } \\
\text { variance }\end{array}$} & 0.2248 & 0.0463 & 0.0590 & 0.1195 \\
\hline & & 20.60 & 26.24 & 53.16 \\
\hline BHPS current income & $y_{p}$ & $\hat{\lambda}_{p} S C_{f i}$ & $\hat{\phi}_{p} X_{p i}$ & $\hat{\varepsilon}_{p i}+\hat{e}_{p i}$ \\
\hline \multirow{2}{*}{$\begin{array}{l}\text { Variance } \\
\text { Percentage of total } \\
\text { variance }\end{array}$} & 0.2715 & 0.0204 & 0.0502 & 0.2009 \\
\hline & & 7.53 & 18.48 & 73.99 \\
\hline \multicolumn{5}{|l|}{ Notes: } \\
\hline \multicolumn{5}{|c|}{$X_{p i}$ for the BHPS is detailed in the notes to Table 1B. } \\
\hline \multicolumn{5}{|c|}{$\begin{array}{l}\text { fathers' employment at } 11 / 10 \text { and } 16 \text {, region at } 11 / 10 \text { and } 16 \text {, housing tenure at } 11 / 10 \text { and } 16 \text {, free } \\
\text { school meals status at } 11 / 10 \text {, lone parent at birth, } 7 / 5 \text { and } 16 \text { and self reported financial difficulties at } \\
16\end{array}$} \\
\hline \multicolumn{5}{|c|}{ 3. Samples: NCDS, 2109, BCS, 1932, BHPS 1206} \\
\hline \multicolumn{5}{|c|}{ 4. Notation refers to notation in text } \\
\hline $\begin{array}{l}\text { Table } 5 \text { is based on b } \\
\text { BHPS. We have expl } \\
\text { influence the broad c } \\
\text { See Blanden et. al. (2 }\end{array}$ & $\begin{array}{l}\text { d convertin } \\
\text { lusion that } \\
\text { ), Appendi }\end{array}$ & $\begin{array}{l}\text { for the coh } \\
\text { BHPS int } \\
\text { HPS and c } \\
\text { ble B4 }\end{array}$ & $\begin{array}{l}\text { continuor } \\
\text { arable ban } \\
\text { ata are sin }\end{array}$ & $\begin{array}{l}\text { ome information in the } \\
\text { find that this does not } \\
\text { in the explored dimensions. }\end{array}$ \\
\hline
\end{tabular}


Table 6: Decomposition of Income Mobility Changes Social class and other permanent income predictors

\begin{tabular}{lllll}
\hline NCDS & $\hat{\lambda}_{s} S C_{s i}$ & $\hat{\phi}_{s} X_{s i}$ & $\hat{\varepsilon}_{s i}+\hat{e}_{s i}$ & Total \\
$\hat{\lambda}_{p} S C_{f i}$ & 0.068 & 0.027 & -0.016 & $\mathbf{0 . 0 7 8}$ \\
$\hat{\phi}_{p} X_{p i}$ & 0.014 & 0.030 & 0.030 & $\mathbf{0 . 0 7 4}$ \\
$\hat{\varepsilon}_{p i}+\hat{e}_{p i}$ & -0.020 & -0.002 & 0.045 & $\mathbf{0 . 0 2 3}$ \\
Total & $\mathbf{0 . 0 6 2}$ & $\mathbf{0 . 0 5 4}$ & $\mathbf{0 . 0 5 9}$ & $\mathbf{0 . 1 7 6}$ \\
\hline BCS & $\hat{\lambda}_{s} S C_{s i}$ & $\hat{\phi}_{s} X_{s i}$ & $\hat{\varepsilon}_{s i}+\hat{e}_{s i}$ & Total \\
$\hat{\lambda}_{p} S C_{f i}$ & 0.054 & 0.033 & 0.006 & $\mathbf{0 . 0 9 3}$ \\
$\hat{\phi}_{p} X_{p i}$ & 0.053 & 0.036 & 0.037 & $\mathbf{0 . 1 2 6}$ \\
$\hat{\varepsilon}_{p i}+\hat{e}_{p i}$ & 0.014 & 0.018 & 0.039 & $\mathbf{0 . 0 7 1}$ \\
Total & $\mathbf{0 . 1 2 0}$ & $\mathbf{0 . 0 8 7}$ & $\mathbf{0 . 0 8 2}$ & $\mathbf{0 . 2 9 0}$ \\
\hline
\end{tabular}

Notes:

1. Sample sizes 2,109 and 1,932

2. Notation refers to notation in text

3. Each cell represents a covariance scaled by the total variance as illustrated in equation (16)

4. $X_{p i}$ for the cohorts is as for Table 5.

5. $X_{s i}$ is the number of GCSEs at grades A-C, number of A-levels, staying on decisions at 16 and 18 , degree attainment, proportion of time spent as a NEET 16-24, housing tenure at 33/30, car ownership at $33 / 30$, pension contributor at $33 / 30$

6. Share of increase in persistence across cohorts from increased persistence in part of income associated with social class $=0.093-0.078=0.015(13 \%$ of total 0.114 increase $)$

7. Share of increase in persistence across cohorts from increased persistence in part of income associated with other income components $=0.126-0.074=0.052(46 \%$ of total 0.114 increase $)$ 
Table 7: Correlations of current income associated with our Xs with permanent and transitory income in the BHPS

\begin{tabular}{lll}
\hline & $\begin{array}{l}\text { Permanent } \\
\text { income } \\
\text { (average) }\end{array}$ & $\begin{array}{c}\text { Transitory income } \\
\text { (current-average) }\end{array}$ \\
\hline $\begin{array}{l}\text { Variables used to predict permanent } \\
\text { income }\end{array}$ & & \\
Mum's education & 0.4337 & -0.0966 \\
Dad's education & 0.4101 & -0.1015 \\
Social housing & -0.3260 & 0.0867 \\
Rented accommodation & -0.0449 & 0.0811 \\
Financial difficulties & -0.3170 & -0.1452 \\
Age & 0.1475 & -0.1161 \\
Variables used to predict transitory & & \\
income & & \\
Dad employed & & \\
Mum employed & 0.1284 & 0.0807 \\
Region & 0.0984 & 0.0961 \\
\hline
\end{tabular}
Notes:

1. All characteristics in the BHPS measured in the last observed period

2. Our sample restriction of two-parent families only prevents us from measuring current lone parent status

3. Transitory income is calculated as the deviation of current income in the last observed period from average income across all observed periods. The correlations are between current income associated with each of the Xs and permanent and transitory income. 
Table 8: Decomposition of Income Mobility Changes Social class, other permanent income predictors and transitory income predictors

\begin{tabular}{lllll}
\hline NCDS & $\hat{\lambda}_{s} S C_{s i}$ & $\hat{\phi}_{s} X_{s i}$ & $\hat{\varepsilon}_{s i}+\hat{e}_{s i}$ & Total \\
$\hat{\lambda}_{p} S C_{f i}$ & 0.068 & 0.027 & -0.016 & $\mathbf{0 . 0 7 8}$ \\
$\hat{\theta}_{p} X_{p i}^{P}$ & 0.017 & 0.026 & 0.026 & $\mathbf{0 . 0 6 8}$ \\
$\hat{\vartheta}_{p} X_{p i}^{T}$ & 0.010 & 0.010 & 0.002 & $\mathbf{0 . 0 2 2}$ \\
$\hat{\varepsilon}_{p i}+\hat{\varphi}_{p i}+\hat{\eta}_{p i}$ & -0.033 & -0.008 & 0.048 & $\mathbf{0 . 0 0 7}$ \\
Total & $\mathbf{0 . 0 6 2}$ & $\mathbf{0 . 0 5 4}$ & $\mathbf{0 . 0 5 9}$ & $\mathbf{0 . 1 7 6}$ \\
\hline BCS & $\hat{\lambda}_{s} S C_{s i}$ & $\hat{\phi}_{s} X_{s i}$ & $\hat{\varepsilon}_{s i}+\hat{e}_{s i}$ & Total \\
$\hat{\lambda}_{p} S C_{f i}$ & 0.054 & 0.033 & 0.006 & $\mathbf{0 . 0 9 3}$ \\
$\hat{\theta}_{p} X_{p i}^{P}$ & 0.050 & 0.032 & 0.033 & $\mathbf{0 . 1 1 6}$ \\
$\hat{\vartheta}_{p} X_{p i}^{T}$ & 0.013 & 0.011 & 0.008 & $\mathbf{0 . 0 3 2}$ \\
$\hat{\varepsilon}_{p i}+\hat{\varphi}_{p i}+\hat{\eta}_{p i}$ & 0.003 & 0.011 & 0.036 & $\mathbf{0 . 0 4 9}$ \\
Total & & & & $\mathbf{0 . 2 9 0}$ \\
\hline
\end{tabular}

Notes:

1. Sample sizes 2,109 and 1,932

2. Notation refers to notation in text

3. Each cell represents a covariance scaled by the total variance as illustrated in equation (19)

4. $X_{p i}^{P}$ : parental education, parental age, maternal employment at birth, $7 / 5$ and $11 / 10$, fathers' employment at 11/10, region at 11/10, housing tenure at 11/10, free school meals status at $11 / 10$, lone parent at birth and $7 / 5$ and self reported financial difficulties at 16

5. $X_{p i}^{T}$ maternal employment 16 , fathers' employment at 16 , region at 16 , housing tenure at 16 and lone parent at 16.

6. $X_{s i}$ as for Table 6.

7. Share of increase in persistence across cohorts from increase in part of income associated with social class $=0.093-0.078=0.015$ ( $13 \%$ of total 0.114 increase)

8. Share of increase in persistence across cohorts from increase in part of income associated with permanent income components $=0.116-0.068=0.048$ ( $42 \%$ of total 0.114 increase)

9. Share of increase in persistence across cohorts from increase in part of income associated with transitory income components $=0.032-0.022=0.010(9 \%$ of total 0.114 increase $)$ 